\title{
Determining the optimal age up to which parents should brush children's teeth
}

\author{
Yukio Machida*1, Hiroshi Sekiguchi*2 and Masashi Yakushiji*2 \\ *1 Professor Emeritus, \\ Tokyo Dental College, \\ *2 Department of Pediatric Dentistry, \\ Tokyo Dental College \\ 1-2-2 Masago, Mihama-ku, Chiba 261-8502, JAPAN
}

\begin{abstract}
We surveyed a group of 56 children (aged 2.3-11.3 years) with complete deciduous or mixed dentition who received brushing instruction three times a year at four-month intervals for 3-9 years. The labial, buccal, lingual, and occlusal surfaces of the deciduous dentition were divided into 20 areas, and those of the mixed or permanent dentition were divided into 28 areas. The age at which children were able to consistently reach all these areas was designated as the age at which children were competent enough to brush their own teeth ("the complete practice age"). Until children reach this stage, parents should brush children's teeth. In this study, the complete practice age was frequently 8-9 years in children who received brushing instruction from before the age of 8 years. However, in children who commenced brushing instruction after the age of 8 years, the complete practice age varied, and an appropriate parental brushing period was difficult to determine. However, no children reached the complete practice age in less than a year after instruction commenced, irrespective of the age that brushing instruction began. Therefore, we suggest that brushing by parents is necessary for at least a year after brushing instruction begins, even in children who begin receiving brushing instruction after the age of 8 years.
\end{abstract}

\author{
Key words \\ Children, \\ Deciduous dentition, \\ Mixed dentition, \\ Parents, \\ Toothbrush
}

\section{Introduction}

The age at which children can manage their own toothbrushing has been determined based on various factors such as the age the children show an interest in brushing, the maturation of neuromuscular function, and the development state of sensory functions ${ }^{1-9)}$, but an accurate determination is difficult by any of these methods.

Therefore, in our survey we divided the maxillary and mandibular dental arches into separate areas, and recorded the age at which children were able to satisfactorily reach all these areas. This was designated as the age up to which parents should brush their children's teeth, or the complete practice age.

Received on September 19, 2007

Accepted on March 3, 2008

\section{Materials and Methods}

The subjects consisted of 56 children (aged 2.3-11.3 years) with complete deciduous or mixed dentitions who received brushing instruction three times a year at four-month intervals for 3-9 years.

As shown in Fig. 1, the labial, buccal, lingual, and occlusal surfaces of the deciduous dentition were divided into 20 areas, and those of the mixed or permanent dentition were divided into 28 areas. The complete practice age was defined as the age at which the children receiving toothbrushing instruction could consistently reach all these areas. Parents should brush their children's teeth up until this age. Observation for determining the complete practice age was performed according to the age at which brushing instruction began. 

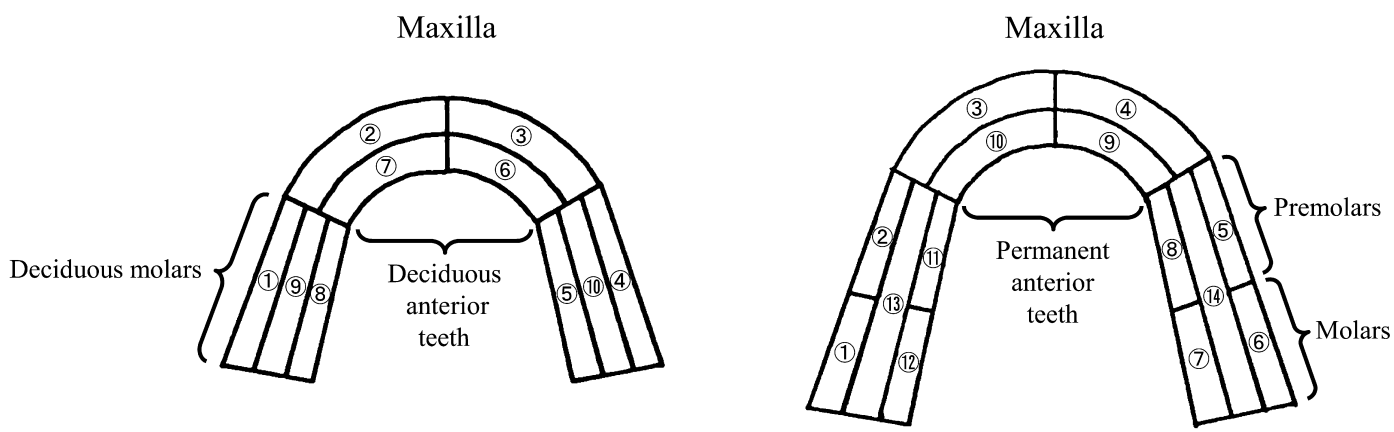

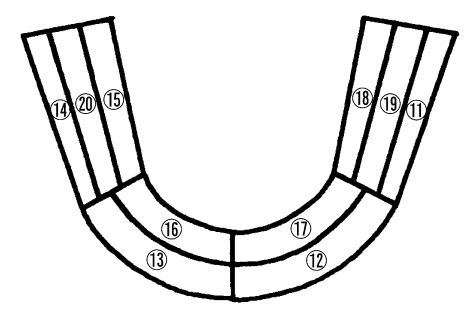

Mandible

Deciduous dentition

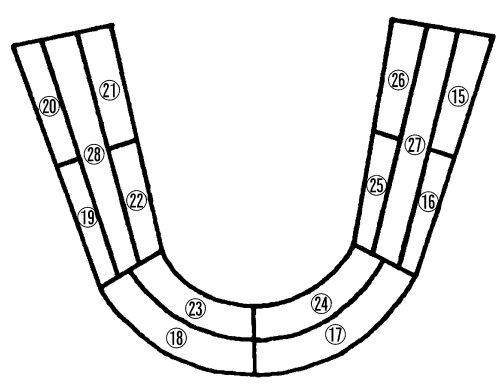

Mandible

Mixed or permanent dentitions

Fig. 1 Method of dividing toothbrush areas in the deciduous, mixed, or permanent dentitions The labial, buccal, lingual, and occlusal surfaces of the deciduous dentition were divided into 20 areas, and those of the mixed or permanent dentition were divided into 28 areas.

Table 1 The complete practice age according to age at the initiation of brushing instruction

\begin{tabular}{|c|c|c|c|c|c|c|c|c|c|c|}
\hline & \multirow{2}{*}{ Age } & \multicolumn{8}{|c|}{ The complete practice age } & \multirow{2}{*}{ Tota } \\
\hline & & 7 & 8 & 9 & 10 & 11 & 12 & 13 & 14 & \\
\hline \multirow{12}{*}{ 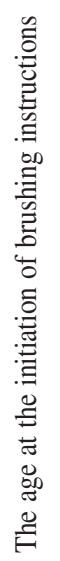 } & 2 & 1 & & & & & & & & 1 \\
\hline & 3 & 2 & & 2 & & & & & & 4 \\
\hline & 4 & 1 & 2 & 3 & & & & & & 6 \\
\hline & 5 & 1 & 1 & 2 & 1 & 4 & 1 & & & 10 \\
\hline & 6 & 1 & 4 & 1 & 2 & 1 & & & & 9 \\
\hline & 7 & & 5 & & & & 2 & & & 7 \\
\hline & Total & 6 & 12 & 8 & 3 & 5 & 3 & & & 37 \\
\hline & 8 & & & 1 & 1 & 2 & 2 & 2 & 2 & 10 \\
\hline & 9 & & & & 1 & 2 & 1 & & 1 & 5 \\
\hline & 10 & & & & & & 2 & 1 & & 3 \\
\hline & 11 & & & & & & & & 1 & 1 \\
\hline & Total & & & 1 & 2 & 4 & 5 & 3 & 4 & 19 \\
\hline
\end{tabular}

\section{Results}

Table 1 shows the complete practice age according to age at the initiation of brushing instruction. In children who began to receive brushing instruction at less than 8 years of age, the complete practice age was often 8 or 9 years. There were no children reached the complete practice age in less than 
a year after the initiation of brushing instruction, irrespective of the age at which brushing instruction commenced.

\section{Discussion}

Based on his clinical experience of providing brushing instruction at four-month intervals, Machida ${ }^{10,11)}$ suggested that brushing by parents is necessary until children reach the age of 8-9 years. In another report, he advocated brushing by guardians until children reach at least 7 years of age. However, his recommendations were based only on clinical experience, and no data was provided. In our study, the complete practice age was frequently $8-9$ years in children who began to receive brushing instructions before the age of 8 years.

Therefore, our findings that brushing by parents is necessary until children reach $7-8$ years of age is consistent with the previous report by Machida ${ }^{10,11}$.

However, children who began receiving brushing instruction after the age of 8 years reached the complete practice age after variable periods, making it difficult to determine the correct time to discontinue parental toothbrushing. However, no children reached the complete practice age in less than a year after instruction commenced, irrespective of the age that brushing instruction began. Therefore, we suggest that brushing by parents is necessary for at least a year after brushing instruction begins, even in children who begin receiving brushing instruction after the age of 8 years.

For children who commence brushing instruction after the age of 8 years, it is optimal to determine the complete practice age by examining each child's ability to consistently clean all of the areas of the dentition as described in our survey.

\section{References}

1) Volker, J.F. and Thomas, J.P.: Clinical Pedodontics. 4th ed. (Finn, S.B. ed.) WB Sanders Company, Philadelphia, 1973, pp. 537-540.

2) Koch, G., Poulsen, S. and Rolla, G.: Pedodontics -A Systematic Approach. 1st ed. (Magnusson, B.G., Koch, G. and Poulsen, S. eds.) Munksgaard, Copenhagen, 1981, pp.11-17.

3) Wei, S.H.Y. and Hyman, R.M.: Pediatric Dentistry - Scientific Foundations and Clinical Practice. (Stewart, R.E., Barber, T.K., Troutman, K.C. and Wei, S.H.Y. eds.) CV Mosby Company, St. Louis, 1982, pp.640-651.

4) Nowak, A.J.: Textbook of Pediatric Dentistry. 2nd ed. (Braham, R.J. and Morris, M.E. eds.) Williams \& Wilkins, Baltimore, 1985, pp. 183-188.

5) Wei, S.H.Y.: Pediatric Dentistry: Total Patient Care. Lea \& Febiger, Philadelphia, 1988, pp.23-31.

6) Mathewson, R.J. and Primosch, R.E.: Fundamentals of Pediatric Dentistry. 3rd ed. Quintessence Publishing Co., Inc., Chicago, 1995, pp.89-93.

7) Andlaw, R.J. and Rock, W.P.: A Manual of Paediatric Dentistry. 4th ed. Churchill Livingstone, New York, 1996, pp.31-36.

8) Dean, J.A. and Hughes, C.V.: Dentistry for the Child and Adolescent. 8th ed. (Mcdonald, R.E., Avery, D.R. and Dean, J.A. eds.) CV Mosby Company, St. Louis, 2004, pp. 256-262.

9) Deery, C. and Toumba, K.J.: Paediatric Dentistry. 3rd ed. (Welbury, R., Duggal, M. and Hosey, M.T. eds.) Oxford University Press Inc., New York, 2005, pp. 116-117.

10) Machida, Y.: A concrete dental plaque control. Dental Outlook 49: 146-151, 1977. (in Japanese)

11) Machida, Y.: A point of toothbrushing instruction for young children. Dental Diamond 15: 46-49, 1990. (in Japanese) 